\title{
Tooling Materials and Solutions for Thixoforming Steel: A key to the process industrialization
}

\author{
RASSILI Ahmed ${ }^{1, a^{*}}$ and LECOMTE-BECKERS Jacqueline ${ }^{2, b}$ \\ ${ }^{1} 4 \mathrm{Bd}$ de Colonster, 4000 Liege, Belgium \\ ${ }^{2} 52$ Avenue des Cherveuilles 4000 Liege, Belgium \\ aa.rassili@ulg.ac.be, bjacqueline.lecomte@ulg.ac.be
}

Keywords: Thixoforming steel, Industrial applications, Heat treatment.

\begin{abstract}
Investigations on steel thixoforming started in the early 90's and many developments were carried out, mainly driven by the industrialization of the process. After a series of basic investigations on adapted steels and materials as well as near-net shaping investigations, the issue of mass production raised and thus induced some other challenges mainly on die life and process automation and cycling. High working temperatures and components complexity were then the main locks to mass productions. In most of reported literature, none of the involved research group reached or real production and industrialization criteria. The euro group holds most of these research investigations [1]. We have reported many of these results in previous communications and this paper presents a continuity of what have already been presented. Some advanced tooling materials and solutions are presented and applied to a real complex industrial component.
\end{abstract}

\section{Introduction}

Thixoforming of high melting point alloys, as steel, is still at the research level. High working temperature, die wearing and production rate are problems that must be solved and are under investigation. The aim of this work is to evaluate the thermal and mechanical loadings applied to the tools during the steel thixoforging process in order to determine appropriate tool materials and solutions.

This evaluation was realized thanks to experimental trials and to the finite elements simulations. The effect of these loadings on the tool's failure modes are highlighted and compared to the ones observed in classical forming processes. Beyond this, the failure modes of different tool materials and solutions are presented. The tested materials are hot-working tool steels. Other possibilities and tool coating or surface treatments are discussed as well.

Due to high slug temperature (usually higher than $1350^{\circ} \mathrm{C}$ ), tools surfaces reach very high temperature. In hot forging, this temperature could already reach $500^{\circ} \mathrm{C}$; in thixoforging, tool temperature increase could reach $700^{\circ} \mathrm{C}$ and even higher. Such a temperature is higher than classical tool steels annealing temperature and could lead to a fall of the mechanical properties. In order to minimize the thermal shocks, dies are usually pre-heated from 40 to $350^{\circ} \mathrm{C}$ in hot forging, but this doesn't prevent the temperature from increasing.

Thixoforging process, as hot forging is composed of three sequential steps:

- Brutal contact of high temperature slug on the tool. If needed, tool closing could be done before or after this step.

- Forming step during which mechanical constraints are applied to the tool.

- Part ejection and tool cooling.

In production, these steps are repeated in a cycle. Tool damaging could be due to different mechanisms: fatigue cracking following thermomechanical loading cycle, microstructure evolution or scaling due to hot working, geometrical modification generated by wearing or plastic deformation. These machanisms are commonly known as: (1) abrasive wearing, (2) thermal fatigue, (3) mechanical fatigue, (4) plastic deformation [1a]. 
In thixoforging, thermomechanical loadings are quite different as forming loads are lower but thermal loads are higher. The failure modes could be different too or simply accentuated. Our previous invesitigations led us to understand some of these mechanisms, the aim of this peper is to apply appropriate solutions to a real industrial case.

\section{Experimental Investigations}

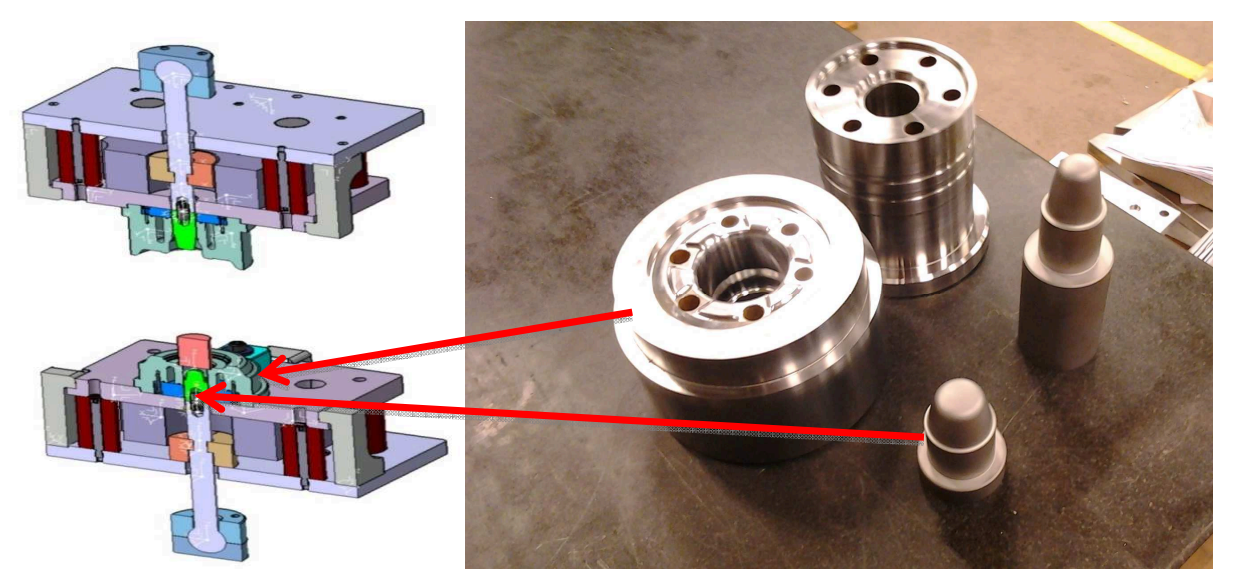

Fig.1 Tool design for experimental investigations, arrows indicate lower die and lower piston.

Tool design. The tool used during this work (Fig. 1) forms an axisymmetric shape part. The deformation is a compression followed by an important reverse than a direct and lateral extrusion. Due to small thickness of the walls, this geometry highlights the thermal and stress effects occurring during forming. The experimental protocol is similar to the one explained in ref [2].

Tool Material. Tool has been made of material $\mathrm{C}$ shown in Fig. 2. The figure shows the yield strength of the investigated tool material $\mathrm{C}$ compared to Z38. A this satge of analysis, we could notice that this material will axhibit a more interesting behaviour at high temperature as its yield strength doesn't drop drastically at $600{ }^{\circ} \mathrm{C}$.

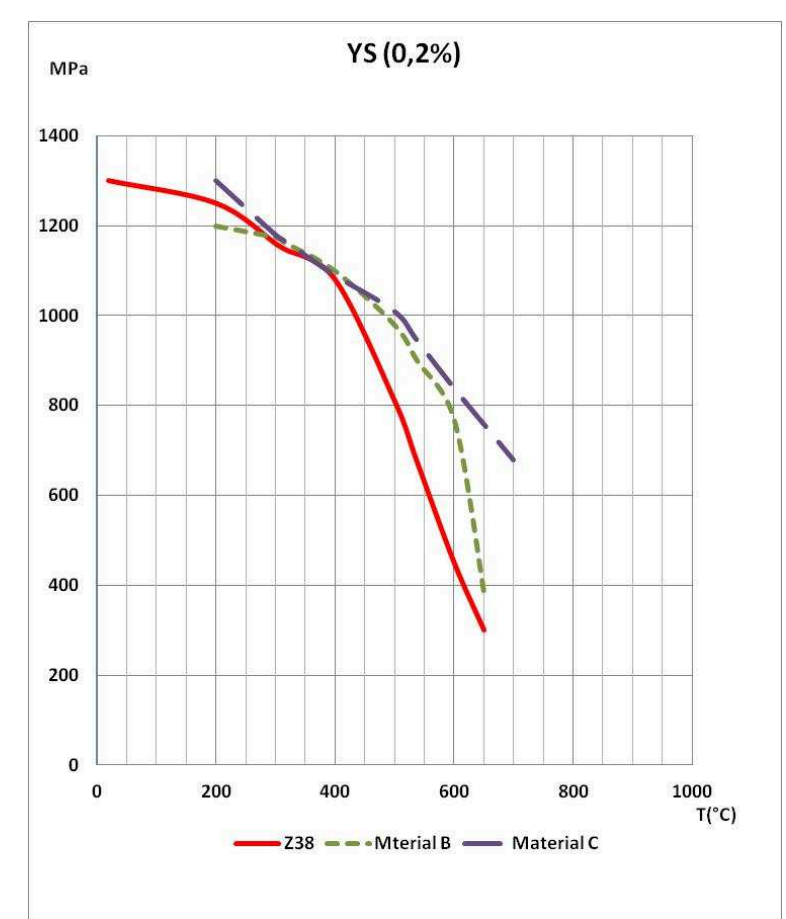

Fig. 2: Yield strength of the investigated tool material C compared to Z38 
Modeling. The Finite Elements code Forge2011 C was used for the simulations. The constitutive law used in this work is quite simple and mainly driven by the liquid fraction, and so the temperature. Thus, the structure of the raw material and its evolution are not explicitly represented. Even if this is a limitation of the calculation results, the error on the flow behavior is small for high solid fraction. Thermal exchanges are already taken into account by the FE code.

The constitutive law is a classical Spittel one (which is the default law used by the solver) when material temperature is lower than solidus and a modification of this Spittel equation when the material temperature is higher than solidus. The modification induces a linear decrease of the consistency by multiplying it by a factor going from one to zero between the solidus and the liquidus. There is then a smooth transition between semi-solid and solid behavior during cooling. A more representative way of modeling could be done by using a two phase model [1b] or a micromacro appraoch [1b].

The constitutive law is

$$
\begin{aligned}
& \sigma=A e^{m 1 T} \mathcal{E}^{m 2} e^{\frac{m 4}{\varepsilon}} \dot{\mathcal{E}}^{m 3} . \\
& \text { for } \mathrm{T}<\text { Tsolidus and } \\
& \sigma=A\left(\frac{T_{l i q}-T}{T_{l i q}-T_{\text {sol }}}\right) e^{m ! T} \mathcal{E}^{m 2} e^{\frac{m 4}{\varepsilon}} \dot{\mathcal{E}}^{m 3}
\end{aligned}
$$

\begin{tabular}{cc}
\hline Parameter & Value \\
\hline $\mathrm{A}$ & 2707.108 \\
$\mathrm{~m} 1$ & -0.00325 \\
$\mathrm{~m} 2$ & -0.00325 \\
$\mathrm{~m} 3$ & 0.1529 \\
$\mathrm{~m} 4$ & -0.05494 \\
$\mathrm{~T}_{\text {sol }}$ & $1315^{\circ} \mathrm{C}$ \\
$\mathrm{T}_{\text {liq }}$ & $1480^{\circ} \mathrm{C}$ \\
\hline
\end{tabular}

In these equations, $\sigma$ is the stress, $\varepsilon$ is the strain, $\dot{\varepsilon}$ is the strain rate, $\mathrm{T}$ is the temperature, $\mathrm{T}_{\text {liq }}$ is the liquidus temperature, $T_{\text {sol }}$ is the solidus temperature and $A, m 1, m 2, m 3$ and $\mathrm{m} 4$ are constants depending on the steel grade. For used steel, the values of the constant parameters are given in Table 1. The values of $\mathrm{A}$ and $\mathrm{m} 1$ to $\mathrm{m} 4$ come from the database of Forge2011 $\mathrm{C}$ and the values of $\mathrm{T}_{\text {liq }}$ and $\mathrm{T}_{\text {sol }}$ have been obtained using thermodynamic claculations and validated by experimental measurments consisting on heating of the slug until the calculated tempertaure followed by a water quenching and than a microscopic analysis of the obtained structure to ensure a coherence between the tempertaure and the working solid-fraction $[3,4]$. Forming boundary conditions are reported on ref [5].

\section{Results and discussion}

Many configurations were simulated and after an optimisation process some were selected for experimental validations. Table 2 summarizes all the simulated cases, which will be discussed according to their relevance.

Thermal loading. The first case consists on evacuating the excess of heat on the die using cooling channels. Figure 3 shows the first step of the process, the slug deposit, inducing the first thermal load on the die. We can easily notice that the temperature increase is localized in a limited region if the die is cooled down but a local high thermal load is still present. 

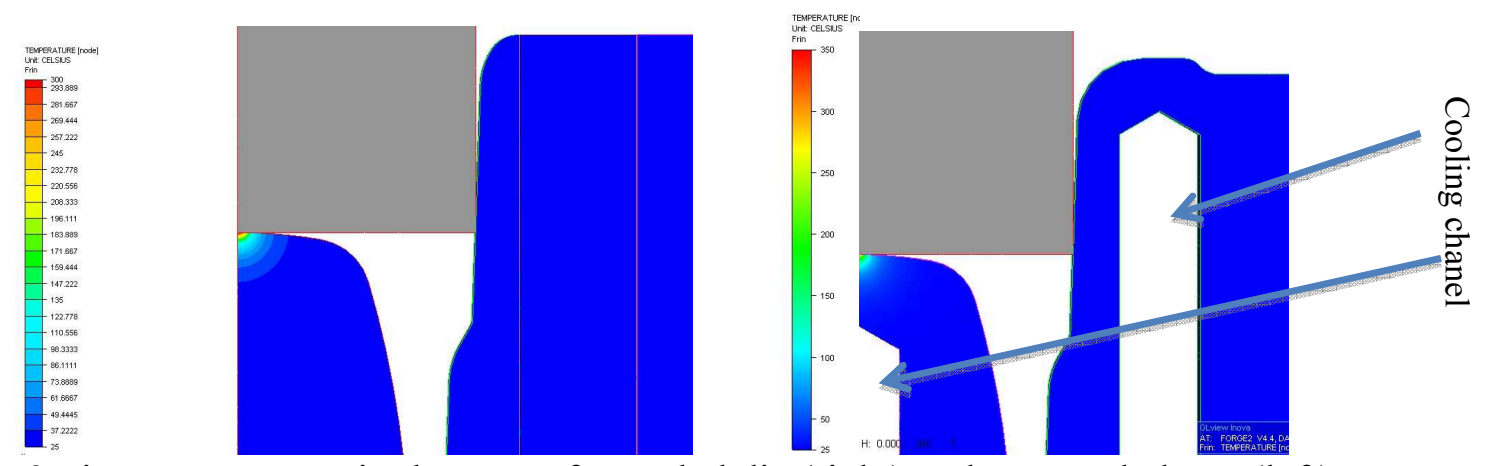

Fig.3 First process step in the case of a cooled die (right) and non cooled one (left)

Table 2: Different simulated configurations for the investigations of tooling solutions, case one is

\begin{tabular}{|c|c|c|c|c|c|c|c|c|c|c|}
\hline \multirow[b]{3}{*}{ 1(ref) } & \multicolumn{3}{|c|}{ Initial die temperature $\left({ }^{\circ} \mathrm{C}\right)$} & \multicolumn{2}{|c|}{ Glass coating } & \multicolumn{2}{|c|}{ Cooling channel } & \multicolumn{3}{|c|}{ Contact time (press type) } \\
\hline & 20 & 180 & 350 & Yes & No & Yes & No & $\begin{array}{c}13 \mathrm{~s} \\
\text { (Hydro) }\end{array}$ & $\begin{array}{c}7 \mathrm{~s} \\
\text { (Hydro) }\end{array}$ & $\begin{array}{c}6.5 \mathrm{~s} \\
\text { (Meca) }\end{array}$ \\
\hline & $\mathrm{x}$ & & & & $\mathrm{x}$ & & $\mathrm{x}$ & $\mathrm{x}$ & & \\
\hline 2 & & $\mathrm{x}$ & & & $\mathrm{x}$ & & $\mathrm{x}$ & $\mathrm{x}$ & & \\
\hline 3 & & & $\mathrm{x}$ & & $\mathrm{x}$ & & $\mathrm{x}$ & $\mathrm{x}$ & & \\
\hline 4 & $\mathrm{x}$ & & & $\mathrm{x}$ & & & $\mathrm{x}$ & $\mathrm{x}$ & & \\
\hline 5 & & $\mathrm{x}$ & & & & $\mathrm{x}$ & & $\mathrm{x}$ & & \\
\hline 6 & & & $\mathrm{x}$ & & & $\mathrm{x}$ & & $\mathrm{x}$ & & \\
\hline 7 & $\mathrm{x}$ & & & & $\mathrm{x}$ & & $\mathrm{x}$ & & $\mathrm{x}$ & \\
\hline 8 & $\mathrm{x}$ & & & & $\mathrm{x}$ & & $\mathrm{x}$ & & & $\mathrm{x}$ \\
\hline 9 & $\mathrm{x}$ & & & $\mathrm{x}$ & & & $\mathrm{x}$ & & $\mathrm{x}$ & \\
\hline
\end{tabular}
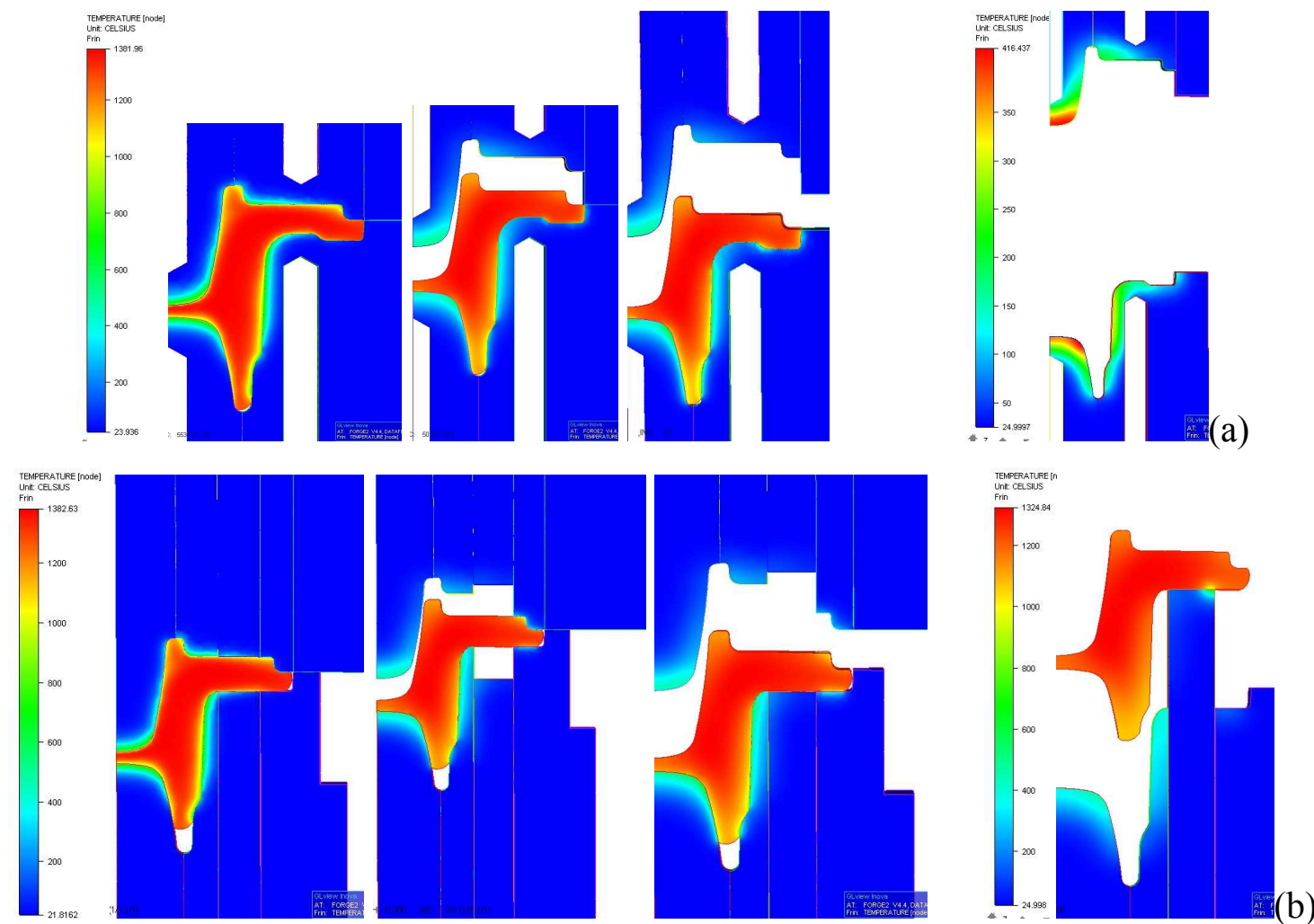

Fig.4 Thixoforming process steps in the case of a cooled die (a) and non-cooled one (b) 
Figure 4 gives the following steps consisting on thixoforming, tool and press opening and convective cooling for the same two cases, (a) non cooled die and (b) cooled one. No significant improvement could be seen and other solutions must than be investigated (Table 2).

We have noticed that the most critical regions of the forming tool are located on the upper surface of the lower piston and lateral surface of the lower die. So we will focus our analysis only to these regions.

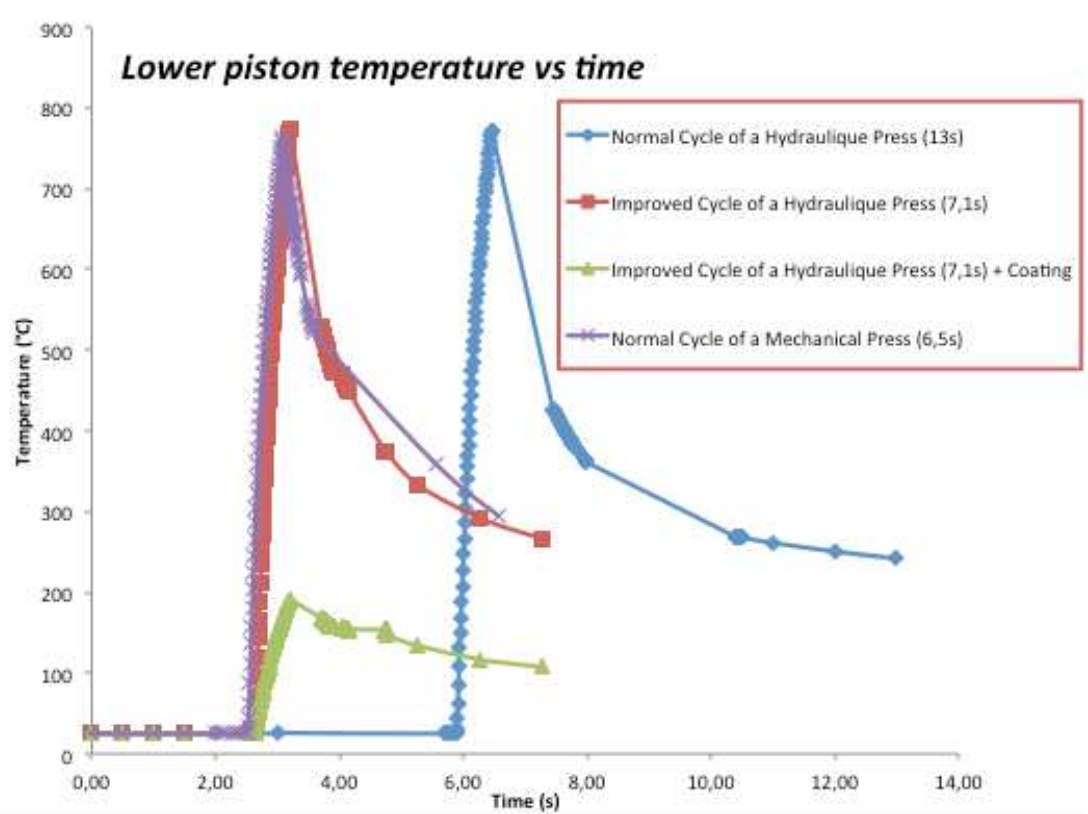

Fig. 5: Temperature of the upper surface of the forming piston along the forming cycle

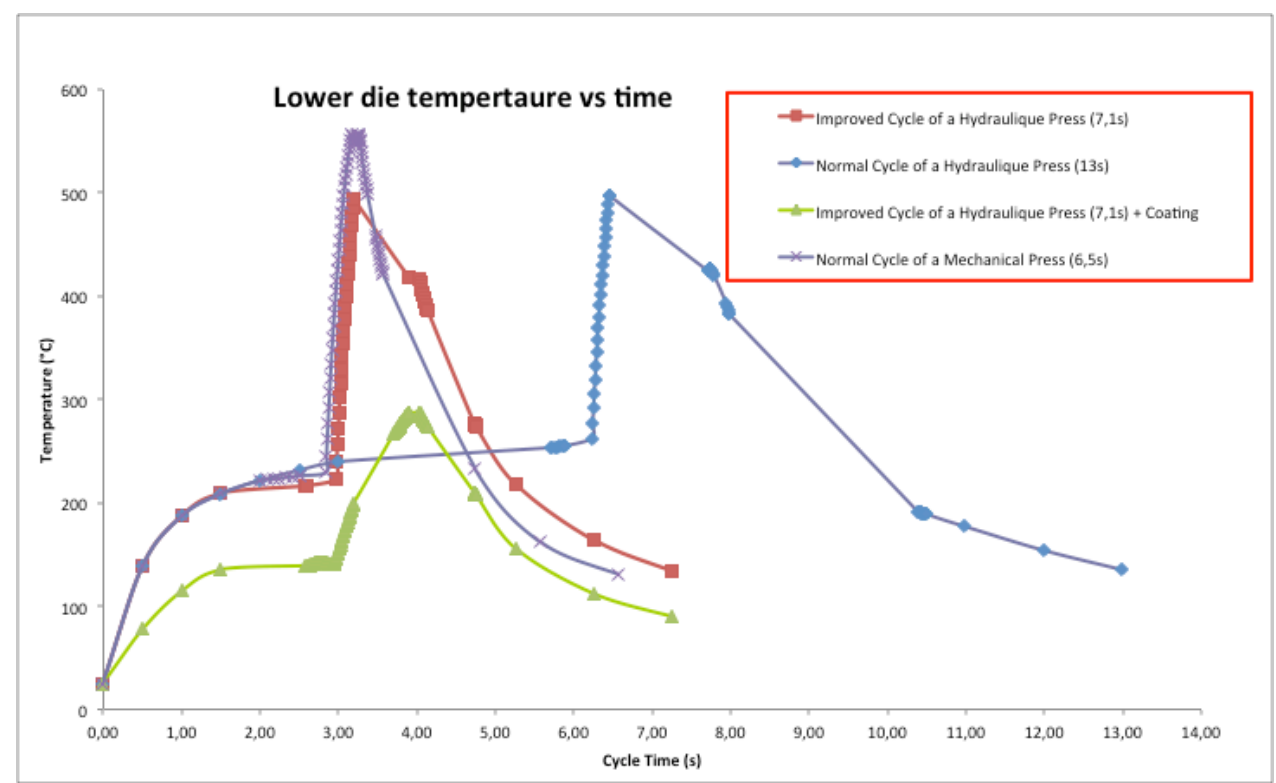

Fig. 6: Temperature of the lateral internal surface of the forming die along the forming cycle

Based on the Yield strengh values of figure 2, optimal working temperature conditions of material $\mathrm{C}$ must be lower than $600^{\circ} \mathrm{C}$ which will have a minor impact on the yield strength.

As shown in Fig. 5 and 6 the comparison of different forming kinematics demonstrates that the hydraulic press could give the same results as a mechanical one in terms or contact time between the slug/part and the die. The main improvement is mainly given by the coating solution that helps maintaining the temperature below the critical one. In the case the lower die improved hydraulic cycle gives better results than the mechanical one. Combined to a coating solution, temperature 
values remain below the Yield stress drop values; the die could be than prevented from plastic deformations.

\section{Mechanical loading.}

For the different cases of Table 2, we have evaluated the Von Mises equivalent stress as shown in Figure 7 for the reference case. The results for the other studied cases are summarized in Table 3 in which are given initial and final temperatures and stresses. In point of view of mechanical loading, the most interesting case is the one combining a hydraulic press cycle and the glass coating which is not an adequate one in terms of contact time, thus case 9 is the most suitable as it combines, a lower contact time, a lower stress on the tool and a lower thermal load.

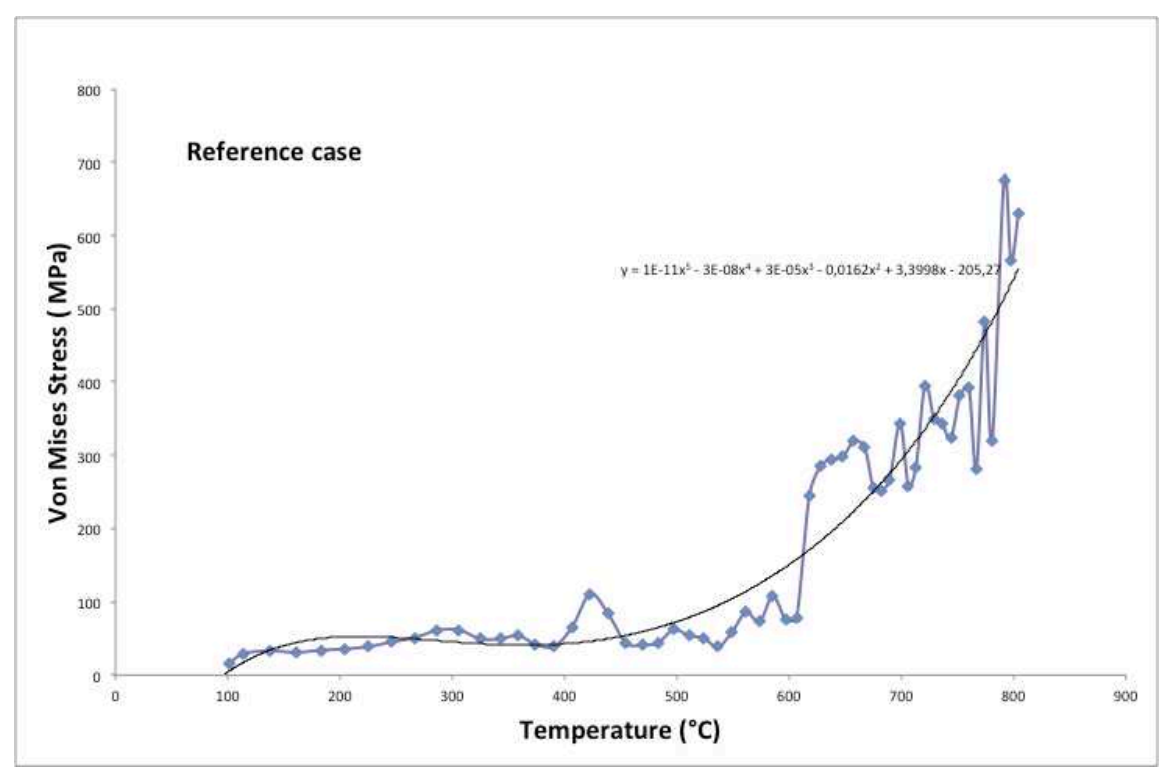

Fig. 7: Reference case for the evolution of Von Mises equivalent stress vs temperature in the piston

Table 3 : Von Mises stress and corresponding temperature in the piston for different cases

\begin{tabular}{|c|c|c|c|c|}
\hline Case & Init $\mathrm{T}\left({ }^{\circ} \mathrm{C}\right)$ & Init Stress(MPa) & Final $\mathrm{T}\left({ }^{\circ} \mathrm{C}\right)$ & Final Stress (Mpa) \\
\hline 2 & 180 & 30 & 850 & 840 \\
\hline 3 & 350 & 30 & 950 & 650 \\
\hline 4 & 25 & 30 & 200 & 325 \\
\hline 5 & 25 & 30 & 800 & 1450 \\
\hline 6 & 100 & 30 & 800 & 680 \\
\hline 7 & 25 & 30 & 780 & 420 \\
\hline 8 & 25 & 30 & 780 & 180 \\
\hline 9 & 20 & 30 & 200 & 350 \\
\hline
\end{tabular}

In an experimental point of view only case 5 , with intitial temperature of $80^{\circ} \mathrm{C}$, was tested and it confirms clearly the simulated results, higher thermal load and higher stress which involves a tool cracking after a series of parts production. Other experimental results with above mentionned improvments are under study and will be presented in future communications.

\section{Conclusions and remarks}

A suitable conbination of different solutions is shown to have a great impact on the tool degradation and thus increasing its life. This issue is the main lock toward the industrialisation of the process. Real industrial applications are now needed to materilaize the research results and applications. 


\section{Acknowledgement}

The authors gratefully acknowledge the University of Liège and the Walloon Region for their financial support as well as partners from CRM, SIRRIS and MK.

\section{References}

[1] H. Atkinson, A. Rassili, Thixoforming steel, Shaker-Verlag, Aachen, 2010.

[1a] H. Atkinson, A. Rassili, Thixoforming steel, Shaker-Verlag, Aachen, 2010, page 105.

[1b]H. Atkinson, A. Rassili, Thixoforming steel, Shaker-Verlag, Aachen, 2010, page 67.

[2] A. Rassili, S. Falzone, J. Lecomte-Beckers, Solid State Phenomena Vols. 192-193 (2012)

[3] D.H. Kirkwood, M. Suéry, P. Kapranos, H.V. Atkinson, Semi-Sold Processing of alloys, Springer, 2010.

[4] J. Lecomte-Beckers, A. Rassili, M. Robelet, C. Poncin, R. Koeune, J. Solid State Phenomena Vols. 116-117 (2006) pp 54-57

[5] J. C. Pierret, A. Rassili, G. Vaneetveld, J. Lecomte-Beckers, P. Cezard and R. Bigot, Springer Editions, International Journal of Material Forming (2008), Vol.1, pp 1011-1014 
Semi-Solid Processing of Alloys and Composites XIII

10.4028/www.scientific.net/SSP.217-218

Tooling Materials and Solutions for Thixoforming Steel: A Key to the Process Industrialization 10.4028/www.scientific.net/SSP.217-218.374 